\title{
ECOLOGIA POPULACIONAL DOS AMPHIPODA (CRUSTACEA) DOS FITAIS DE CAIOBÁ, MATINHOS, PARANÁ, BRASIL
}

\author{
Janete Dubiaski-Silva ${ }^{2}$ \\ Setuko Masunari ${ }^{2}$
}

\begin{abstract}
POPULATION ECOLOGY OF AMPHIPODA (CRUSTACEA) FROM THE PHYTALS of Calobá, Matinhos, Paraná, Brazil. Spatial and temporal density distributions of Amphipoda from the phytals of Caiobá are described. Air temperature oscillated from $16^{\circ} \mathrm{C}$ (August and May) to $23^{\circ} \mathrm{C}$ (March), surface water temperature from $17^{\circ} \mathrm{C}$ (August) to $25^{\circ} \mathrm{C}$ (March) and the salinity from $29.3 \%$ (May) to $32.8 \%$ (August). Two samples of $25 \mathrm{~cm}^{2}$ (for algae less than $5 \mathrm{~cm}$ long), $100 \mathrm{~cm}^{2}$ (for algae between $5-10 \mathrm{~cm}$ long) and whole plants (for algae more than $10 \mathrm{~cm}$ long) were removed with a spatula from the rocky surface at Caiobá Beach, in August/86, November/86, March/87 and May/87. After sorting, the algal substrata were weighted, their adsorption coefficient calculated and the sediment retained among the thallii weighted. The average distance between the branching was measured for all branched algae. The densities were calculated in relation to the weight of the algal substrate in grams. Eight phytals were considered: Ulva fasciata Delile, Padina gymnospora (Kútzing) Vickers, Sargassum cymosum Garth, Porphyra atropurpurea (Olivi) De Toni, Gelidium sp., Gymnogongrtus griffithsiae (Turner) Martius, Pterocladia capillacea (Gmelin) Bornet \& Thuret and Pterosiphonia pennata (Roth) Falkenberg, over which nine Amphipoda species live: Ampithoe ramondi Audouin, 1816. Cymadusa filosa Savigny, 1852, Elasmopus pectenicrus Bate, 1857. Hyale media Dana, 1857, Hyale sp.1, Jassa falcata Montagu, 1895 and Stmampithoe pelagica H. Milne-Edwards, 1830 (Gammaridea), Caprella danilevskii Czerniavski, 1861 and Caprella penantis Leach, 1814 (Caprellidea). Amphipoda densities ranged from 0.27 ind. $\mathrm{g}^{-1}$ to 45.68 . ind. $\mathrm{g}^{-1}$. The broad-thallii algae Porphyra, Ulva and Padina harbored lower densities of Amphipoda, whereas those finely branched Pterocladia, Pterosiphonia and Gymnogongrus, the highest values and the less branched Sargassum and Gelidium, intermediate values. The high densities found in the finely branched algae had as main contribution the juvenile recruiting of most Amphipoda. The tide level might have influenced the temporal distribution of the Amphipoda density, due to the distinct time of air exposition in each collection data. Most Amphipoda did not show specific algal substratum colonization: only Sunampithoe pelagica occurred solely in Sargassum. Four species occurred in different branched algae: $J$. falcata, $S$. pelagica, $C$. danilevskii and $C$. penantis. $H$. media had Sargassum, Pterocladia, Pterosiphonia and Gymnogongrus as the best algal substrata, whereas Caprellidea, the Pterocladia and Pterosiphonia phytals. High sediment weight in Padina was the main reason for high densities of Hyale sp. 1 in this phytal. The occurrence of males, females (including ovigerous ones) and juveniles of most Amphipoda species found in the present study indicates a complete life cycle whithin these phytals and corroborates with the assumption of the complexity of this marine coastal ecosystem.
\end{abstract}

KEY WORDS. Amphipoda, phytal, density, population, Caiobá, Paraná, Brazil

1) Contribuição número 880 do Departamento de Zoologia, Universidade Federal do Paraná.

2) Departamento de Zoologia, Universidade Federal do Paraná. Caixa Postal 19020, 81531-990 Curitiba, Paraná, Brasil. 
Em 1933, Remane (apud MASUnARI \& FORNERIS 1981) propôs o termo fital para designar um ambiente marinho litoral, distinto do pelagial e do bental. Este biótopo é dominado por macrófitas (algas marinhas, gramas marinhas ou liquens) que propiciam moradia, refúgio e alimentação para os seres vivos associados a elas (DAHL 1948).

MASUNARI (1987) realizou uma ampla revisão bibliográfica sobre os avanços nas análises estrutural e funcional das comunidades fitais. A partir desta publicação citam-se, entre outros, autores como RYER \& ORTH (1987), GIBBONS (1988b) e RYER (1988) que estudaram aspectos sobre a predação de Amphipoda por peixes. Estudos sobre relações com o grau de exposição às ondas e distribuição vertical da fauna fital foram realizados por GiBBONS (1988a) e MAZZELLA et al. (1989). Investigações sobre a relação entre a abundância de espécies de Amphipoda e a biomassa e complexidade estrutural do habitat foram feitas por HACKER \& STENECK (1990) e LEWIS (1987). BRAWLEY \& FEY (1987) analizaram a influência de alguns Caprellidae sobre o epifitismo nas comunidades fitais. A resistência às defesas químicas de algas contra peixes e o potencial de impacto de vários Amphipoda sobre Sargassum filipendula $\mathrm{C}$. Agardh foram realizadas por HAY et al. (1987a,b; 1988a,b) e DuFFY (1990), respectivamente.

O fital constitui um dos ambientes menos conhecidos do litoral paranaense, havendo poucos estudos sobre ele. JAKOBI $(1954,1962)$ e LOYOLA E SiLVA (1960) estudaram, respectivamente, os Copepoda Harpacticoidea e Isopoda de fitais variados. Dutra (1988) investigou a flutuação anual da densidade dos animais vágeis de Pterocladia capillacea (Hudson) Papenfuss da Ilha do Mel e MASUNARI (1986) enfocou aspectos ecológicos dos Copepoda Harpacticoidea dos fitais de Caiobá.

Neste ecossistema foram registradas as maiores densidades de animais potencialmente pertencentes às bases das cadeias alimentares marinhas. Sendo os Amphipoda numericamente expressivos no fital, a sua participação na cadeia trófica das comunidades marinhas costeiras foi diretamente relacionada à produção pesqueira (KIKUCHI \& PÉRÈS 1977).

O presente trabalho tem por finalidade descrever a composição específica dos Amphipoda Gammaridea e Caprellidea e a respectiva distribuição espacial e temporal de densidade relacionadas com os parâmetros abióticos mais conspícuos dos fitais de Caiobá, Paraná.

\section{MATERIAL E MÉTODOS}

Devido à riqueza e abundância de fitais aliadas à facilidade de acesso para as amostragens, foi escolhido como local de coleta o substrato rochoso da praia de Caiobá, Matinhos, e do dique que liga esta com a Ilha do Farol (Fig. 1). Costões rochosos e matacões assentados sobre um substrato arenoso caracterizam a praia de Caiobá, ao passo que o dique é formado por seixos e matacões que ficam emersos durante as marés vazantes de sizígia. As diferentes algas crescem sobre o substrato rochoso em forma de manchas irregulares ou, quando abundantes, em tapetes de grande extensão na faixa do mediolitoral. 
Durante o período de agosto de 1986 a maio de 1987, foram realizadas quatro coletas programadas de acordo com a maré mais baixa do mês prevista nas Tábuas de Marés (DHN 1986, 1987) nas seguintes datas: 06-VIII-86, 01-IX-86, $15-$ III-87 e $28-\mathrm{V}-87$.

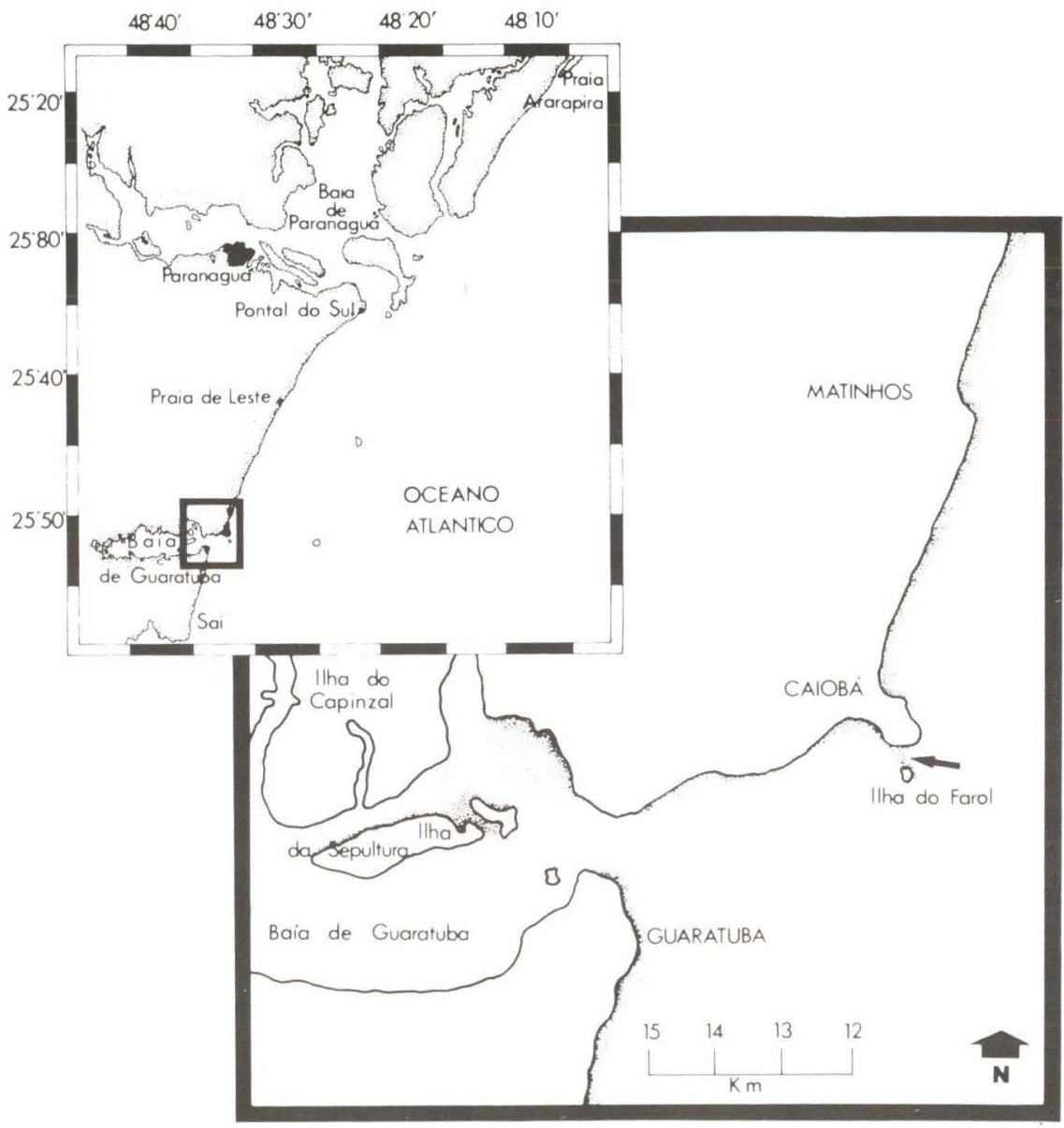

Fig. 1. Mapa da porção oriental do Estado do Paraná e sul do litoral paranaense. A área de coleta (seta) compreende os costões rochosos da praia de Caiobá no continente e os blocos rochosos que formam o dique que liga a llha do Farol ao continente. Durante as preamares, o dique fica totalmente submerso.

Foram coletadas duas amostras das algas mais exuberantes, raspando-se o apressório da rocha com o auxílio de uma espátula e, de acordo com o comprimento da fronde, foram utilizados: a) quadrados de $5 \mathrm{~cm}$ de lado para algas com menos de $5 \mathrm{~cm}$ de comprimento; b) quadrados de $10 \mathrm{~cm}$ de lado para algas com comprimento entre $5 \mathrm{~cm}$ e $10 \mathrm{~cm} \mathrm{e} \mathrm{c)} \mathrm{planta} \mathrm{inteira} \mathrm{para} \mathrm{algas} \mathrm{com} \mathrm{comprimento} \mathrm{superior}$ 
a $10 \mathrm{~cm}$. As amostras foram imediatamente colocadas em sacos plásticos e acondicionadas em uma caixa de isopor contendo gelo, para posterior fixação e conservação em álcool $70 \%$. Foram tomadas, ainda, as temperaturas do ar e da água de superfície e coletadas amostras da água de superfície para posterior medida da salinidade, com um salinômetro digital Digimed.

A triagem do material foi feita sob microscópio estereoscópico; as densidades animais foram calculadas em relação ao peso das algas-substrato ( $\mathrm{n}^{\circ}$ ind. $\mathrm{g}^{-1}$ ) e os coeficientes de adsorção das mesmas foram obtidos segundo WIESER (1951), o qual se baseou no peso relativo (em percentagem) da água retida entre os talos. As medidas dos espaços entre as ramificacões das algas foram feitas sob microscópio estereoscópico equipado com ocular graduada. Seguiu-se DAHL (1948) para o cálculo de sedimento retido nas algas: o peso do sedimento em miligramas em relação ao peso da alga-substrato em gramas $\left(\mathrm{mg} \cdot \mathrm{g}^{-1}\right)$.

\section{RESULTADOS}

A temperatura do ar obtida nas quatro coletas realizadas oscilou entre $16^{\circ} \mathrm{C}$ (agosto e maio) e $23^{\circ} \mathrm{C}$ (março). Estes valores mostram-se bastante próximos das temperaturas médias mensais para Paranaguá, cidade mais próxima de Caiobá. A temperatura do ar nestas amostragens, também, esteve sempre próxima $\left(1^{\circ}\right.$ a $3^{\circ} \mathrm{C}$ menor) à da temperatura da água de superfície, que variou entre $17^{\circ} \mathrm{C}$ (agosto) e $25^{\circ} \mathrm{C}$ (março). Desta forma, pode-se inferir que a temperatura do ar de novembro deve ter um valor próximo ao da temperatura média do mês de novembro em Paranaguá. Da mesma forma, o tempo por ocasião da amostra de maio concorda com os dados fornecidos pelo Instituto Nacional de Meteorologia para Paranaguá: maio foi o mês de maior precipitação pluviométrica e com maior número de dias com chuva dentre os meses de amostragem (Tabs I e II).

Tabela I. Caiobá. Altura das marés previstas para a Barra do Porto de Paranaguá-Canal da Galheta, PR, valores de temperatura do ar, temperatura e salinidade da água de superfície e tempo no dia das amostragens.

\begin{tabular}{|c|c|c|c|c|c|}
\hline $\begin{array}{l}\text { Data da } \\
\text { coleta }\end{array}$ & $\begin{array}{l}\text { Altura da maré } \\
\qquad(\mathrm{m})\end{array}$ & $\begin{array}{l}\text { Temperatura do ar } \\
\qquad\left({ }^{\circ} \mathrm{C}\right)\end{array}$ & $\begin{array}{c}\text { Temperatura da } \\
\text { água }\left({ }^{\circ} \mathrm{C}\right)\end{array}$ & $\begin{array}{c}\text { Salinidade } \\
(\$ 6) \mid\end{array}$ & $\begin{array}{c}\text { Clima no dia da } \\
\text { coleta }\end{array}$ \\
\hline $06-V I I-86$ & 0,0 & 16,0 & 17,0 & 32,8 & Nublado \\
\hline $01-x 1-86$ & 0,0 & - & 24,0 & 30,7 & Bom com sol \\
\hline $13-111-87$ & 0,2 & 23,0 & 25,0 & 30,7 & Bom com sol \\
\hline $28-111-87$ & 0,0 & 16,0 & 19,0 & 29,3 & Chuva fraca \\
\hline
\end{tabular}

A salinidade oscilou de $29,3 \%$ (maio) a $32,8 \%$ o (agosto), valores que corresponderam, respectivamente, ao maior $(227 \mathrm{~mm})$ e ao menor $(100 \mathrm{~mm})$ índices de precipitação pluviométrica mensal (Tabs I e II).

Os limites da altura da maré variaram de $0,0 \mathrm{~m}$ (agosto, novembro e maio) a $0,2 \mathrm{~m}$ (março) nas datas de coleta. Em maio, embora a previsão da altura da maré fosse de $0,0 \mathrm{~m}$, visivelmente a maré não abaixou até esta altura, fato relacionado ao tempo chuvoso. Em novembro/86, foi registrado o maior número de dias com 
maré inferior a $0,0 \mathrm{~m}$ de altura durante o período diurno (17 dias), seguido de agosto/86 (13), março/87 (9) e maio/87 (7).

Tabela II. Paranaguá. Temperaturas médias, máximas e mínimas, precipitação pluviométrica média (PPT), número de dias com chuva e número de dias com maré prevista inferior a 0,0 $\mathrm{m}$ de altura (MPI 0,0), nos meses de amostragem (INEMET e DHN).

\begin{tabular}{lcccccc}
\hline $\begin{array}{c}\text { Mês de } \\
\text { coleta }\end{array}$ & $\begin{array}{c}\text { Temp. méd. } \\
\left({ }^{\circ} \mathrm{C}\right)\end{array}$ & $\begin{array}{c}\text { Temp. máx. } \\
\left({ }^{\circ} \mathrm{C}\right)\end{array}$ & $\begin{array}{c}\text { Temp. mín. } \\
\left({ }^{\circ} \mathrm{C}\right)\end{array}$ & $\begin{array}{c}\text { PPT } \\
(\mathrm{mm})\end{array}$ & $\begin{array}{c}\text { Número de dias } \\
\text { com chúmero de dias }\end{array}$ & $\begin{array}{c}\text { MPI } 0,0 \\
\text { chuva }\end{array}$ \\
\hline Agosto/86 & 18,50 & 24,00 & 15,00 & 100 & 11 & 13 \\
Novembro/86 & 22,53 & 27,85 & 19,08 & 178 & 17 & 17 \\
Março/87 & 23,59 & 29,46 & 19,73 & 140 & 9 & 9 \\
Maio/87 & 17,90 & 22,60 & 14,60 & 227 & 14 & 7 \\
\hline
\end{tabular}

Foram coletadas oito espécies de alga-substrato durante o período de amostragem: Ulva fasciata Delile, Padina gymnospora (Kützing) Vickers, Sargassum cymosum Garth, Porphyra atropurpurea (Olivi) De Toni, Gelidium sp., Pterocladia capillacea (Gmelin) Bornet \& Thuret, Gymnogongrus griffithsiae (Turner) Martius e Pterosiphonia pennata (Roth) Falkenberg, as quais serão referidas pelo gênero no presente trabalho.

A distribuição vertical das algas estudadas segue o padrão descrito para o litoral paulista por NONATO \& PÉrÈs (1961), OliveIRA-Filho \& MAYAL (1976) e por JOLY (1965) e para o litoral paranaense descrito por JOLY (1951): Porphyra Agardh ocupa as partes mais altas das rochas, Ulva Linnaeus apresenta uma ampla distribuição nos estratos superior e médio do mediolitoral, Gymnogongrus Martius, Padina Adanson e Gelidium Lamouroux crescem em níveis intermediários e Sargassum C. Agardh e Pterosiphonia Falkenberg in Schmitz ocorrem no limite inferior com o infralitoral. Sargassum, Gelidium, Pterocladia J. Agardh, Pterosiphonia e Gymnogongrus foram registrados em todas as coletas realizadas. Ulva não ocorreu em maio e Padina em agosto. Porphyra foi registrada apenas em agosto e novembro.

Das algas-substrato registradas, três possuem talos foliáceos: Porphyra, Ulva e Padina. As demais são ramificadas e a distância média entre suas ramificações, segundo a análise de variância (One-Way Anova), apresentou diferenças significativas de um grupo de alga para outro. O teste complementar de Duncan (DMS $=4,74$ ) demonstrou que Gelidium e Sargassum são as algas menos ramificadas, não diferindo significativamente entre si. Pterocladia apresenta um grau de ramificação intermediário e Pterosiphonia e Gymnogongrus são as algas mais ramificadas, não diferindo significativamente uma da outra (Fig. 2).

Padina apresentou o maior coeficiente de adsorção dentre as algas estudadas com o valor de 64,00\%, seguindo-se Pterosiphonia (63,04\%), Porphyra (62,13\%), Gymnogongrus (57,66\%), Pterocladia $(56,70 \%)$, Ulva $(54,46 \%)$, Sargassum (28,88\%) e Gelidium (16,87\%). Estes valores referem-se à média dos coeficientes de adsorção das quatro épocas do ano. Algas foliáceas e finamente ramificadas mostraram retenção de maior volume de água do mar nos seus talos (Fig. 2). 
Tabela 111. Fitais de Caiobá. Forma e morfometria do talo, distäncia média entre as ramificaçoes e coeficientes de adsorção das algas-substrato (C.A.), densidade total e nuimero de espécies de Amphipoda e peso de sedimento (escala é a mesma em todos os gráficos) nas amostras de inverno/86, primavera/86, veräo/87 e outono/87.

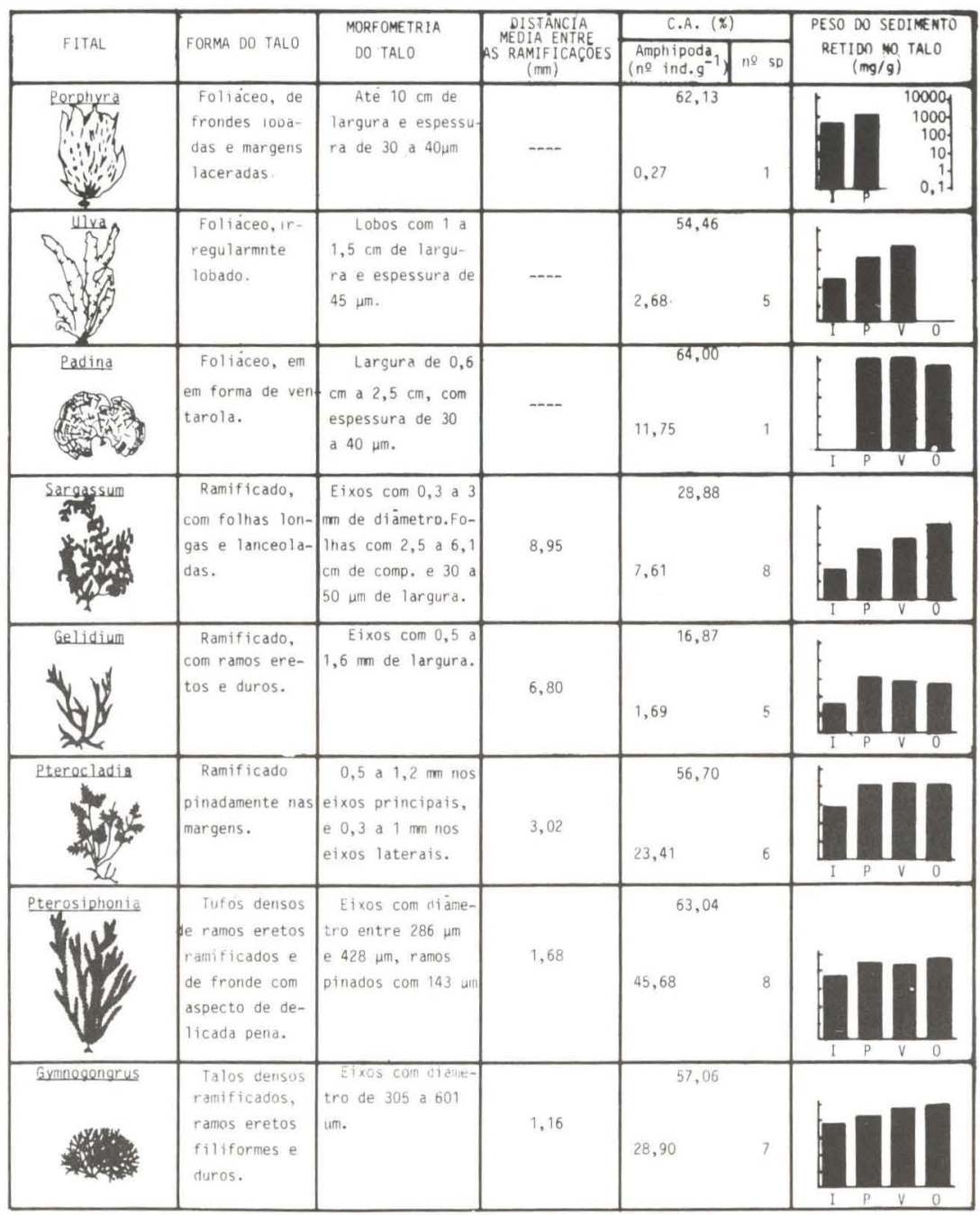

Fig. 2. Fitais de Caiobá. Forma e morfometria do talo, distância média entre as ramificações e coeficientes de adsorção das algas-substrato (C.A.), densidade total e número de espécies de Amphipoda e peso de sedimento (a escala é a mesma em todos os gráficos) nas amostras de agosto/86, novembro/86, março/87 e maio/87.

O peso de sedimento apresentou variações significativas em cada espécie de alga nas quatro coletas realizadas. Porém, comparando seus valores médios, no período estudado, a ordem decrescente nos fitais de Caiobá foi: Padina > Gymnogongrus e Pterosiphonia $>$ Porphyra $>$ Pterocladia e Ulva $>$ Sargassum 
e Gelidium. As algas ramificadas mostraram uma tendência a uma correlação positiva entre a quantidade de sedimento e o grau de ramificação dos talos (Fig.2).

Pode-se inferir desta maneira que as características microambientais em cada fital estão relacionadas principalmente com a forma do talo das algassuhstrato, embora a quantidade de sedimento retido nas mesmas sofra influência de fatores além da forma da alga (houve oscilação dos valores entre as coletas).

Sete espécies de quatro familias de Amphipoda Gammaridea foram registradas nestes fitais: Ampithoe ramondi Audouin, 1816, Cymadusa filosa Savigny, 1852 e Sunampithoe pelagica H. Milne-Edwards, 1830 (Ampithoidae); Elasmopus pectenicrus Bate, 1857 (Gammaridae); Hyale media Dana,1857 e Hyale sp. 1 (Hyalidae) e Jassa falcata Montagu, 1895 (Ischyroceridae). Quanto aos Caprellidea, foram encontradas duas espécies da família Caprellidae: Caprella danilevskii Czerniavski, 1861 e Caprella penantis Leach, 1814.

A amplitude de variação da densidade média dos Amphipoda foi de 0,27 ind. $\mathrm{g}^{-1}$ em Porphyra a 45,68 ind.g $\mathrm{g}^{-1} \mathrm{em}$ Pterosiphonia. De um modo geral, algas ramificadas abrigaram maior número de Amphipoda do que as foliáceas. Entretanto, em Padina (talo foliáceo), houve a quarta densidade mais alta representada exclusivamente por Hyale sp. 1 (Fig. 2). O fator forma do talo da alga foi o mais importante na distribuição de densidade dos Amphipoda, sobrepujando outros como a temperatura, pluviosidade, salinidade, altura da maré e quantidade de sedimento retido nas algas-substrato.

\section{RIQUEZA DE ESPÉCIES DE AMPHIPODA NOS FITAIS}

Os fitais Porphyra e Padina abrigaram uma única espécie: Hyale sp. 1. Entretanto, este Amphipoda ocorreu no primeiro em baixas densidades, talvez, devido à ocorrência inconstante da alga-substrato. Em contraste, Padina mostrou ser um substrato adequado para Hyale sp. 1 que parece ser influenciado pela grande quantidade de sedimento presente na amostra (Fig. 2). A favor desta hipótese, quando não houve registro de Padina (agosto), a espécie ocorreu preferencialmente em Gymnogongrus que acumulou mais sedimento do que Sargassum.

Em Ulva ocorreram cinco espécies, todas Gammaridea em densidades baixas. A análise da estrutura populacional destas espécies mostrou que a proporção de adultos é mais alta neste fital do que nos de talos ramiticados (Tabs III-XI).

Sargassum e Pterosiphonia abrigaram igualmente oito espécies de Gammaridea e Caprellidae; só não ocorreu Cymadusa filosa em Sargassum e Sunampithoe pelagica em Pterosiphonia. Entretanto, as densidades em Pterosiphonia foram muitas vezes superiores devido, provavelmente, à sua ramificação fïna, que se mostrou adequada à colonização de juvenis de várias espécies de Amphipoda, especialmente Hyale media. Além disso, Pterosiphonia compartilha com Pterocladia no oferecimento de abrigo para Caprella penantis. O coeficiente de adsorção que foi discrepante nos dois fitais, não deve ter influído na distribuição dos Amphipoda, uma vez que estas algas ocorrem no mesmo nível em relação à altura da maré. A ocorrência de Sunampithoe pelagica, tanto de adultos como de juvenis, em Sargassum nas quatro coletas realizadas indica a única especificidade entre uma alga-substrato e um Amphipoda no presente estudo. 
Tabela III. Ampithoe ramondi. Densidade $\left(n^{\circ}\right.$ ind. $\left.g^{-1}\right)$ de machos (M), fêmeas (F) e juvenis (J) dos fitais de Caiobá nas amostras de agosto/86, novembro/86, março/87 e maio/87.

\begin{tabular}{|c|c|c|c|c|c|c|c|c|c|c|c|c|}
\hline \multirow{2}{*}{ Fital } & \multicolumn{3}{|c|}{ Agosto/86 } & \multicolumn{3}{|c|}{ Novembro/86 } & \multicolumn{3}{|c|}{ Marco/87 } & \multicolumn{3}{|c|}{ Maio/87 } \\
\hline & $M$ & $\mathrm{~F}$ & $\mathrm{~J}$ & $M$ & $\mathrm{~F}$ & J & $M$ & $\mathrm{~F}$ & $J$ & $M$ & $\mathrm{~F}$ & J \\
\hline Porphyra & - & - & - & - & . & - & * & - & - & - & . & * \\
\hline UIva & 0,03 & 0,19 & 0,10 & 0.03 & 0,15 & 0,03 & - & . & . & · & . & * \\
\hline Padina & $\cdot$ & * & $\cdot$ & - & . & - & - & & - & - & & - \\
\hline Sargassum & 0,01 & 0,03 & 0,01 & . & . & - & - & - & - & - & 0,06 & - \\
\hline Gelidium & · & 0,01 & 0,01 & . & - & • & . & . & . & - & · & - \\
\hline Pterocladia & . & - & - & . & . & 0,78 & . & - & . & - & 0,09 & 0,26 \\
\hline Pterosiphonia & - & - & - & . & . & - & - & 0,11 & - & - & · & - \\
\hline Gymnogongrus & - & 0,56 & 1,35 & - & . & - & - & - & . & - & 0,56 & - \\
\hline
\end{tabular}

*. Algas não registradas.

Tabela IV. Cymadusa filosa. Densidade $\left(n^{\circ}\right.$ ind. $\left.g^{-1}\right)$ de machos $(M)$, fêmeas $(F)$ e juvenis (J) dos fitais de Caiobá nas amostras de agosto/86, novembro/86, março/87 e maio/87.

\begin{tabular}{|c|c|c|c|c|c|c|c|c|c|c|c|c|}
\hline \multirow{2}{*}{ Fital } & \multicolumn{3}{|c|}{ Agosto/86 } & \multicolumn{3}{|c|}{ Novembro/86 } & \multicolumn{3}{|c|}{ Março/87 } & \multicolumn{3}{|c|}{ Maio/87 } \\
\hline & $M$ & $\mathrm{~F}$ & J & M & $\mathrm{F}$ & $J$ & $M$ & $\mathrm{~F}$ & $\mathrm{~J}$ & M & $\mathrm{F}$ & $J$ \\
\hline Porphyra & $\cdot$ & $\cdot$ & $\cdot$ & . & - & - & * & * & • & • & * & * \\
\hline Uiva & 0,08 & 0,08 & 0,99 & & & - & . & - & - & * & * & * \\
\hline Padina & $\cdot$ & * & $\cdot$ & - & - & - & - & - & - & - & & - \\
\hline Sargassum & - & - & - & - & - & . & . & . & - & - & . & - \\
\hline Gelidium & . & - & - & - & - & - & - & - & - & - & . & - \\
\hline Pterocladia & - & - & - & - & - & - & - & - & - & - & - & - \\
\hline Pterosiphonia & - & - & - & - & - & - & - & - & - & - & - & 0,16 \\
\hline Gymnogongrus & - & - & 0,56 & - & . & . & - & - & - & - & - & - \\
\hline
\end{tabular}

*. Algas não registradas.

Tabela V. Elasmopus pectenicrus. Densidade $\left(n^{\circ}\right.$ ind. $\left.\mathrm{g}^{-1}\right)$ de machos (M), fêmeas (F) e juvenis $(\mathrm{J})$ dos fitais de Caiobá nas amostras de agosto/86, novembro/86, março/87 e maio/87.

\begin{tabular}{|c|c|c|c|c|c|c|c|c|c|c|c|c|}
\hline \multirow{2}{*}{ Fital } & \multicolumn{3}{|c|}{ Agosto/86 } & \multicolumn{3}{|c|}{ Novembro/86 } & \multicolumn{3}{|c|}{ Março/87 } & \multicolumn{3}{|c|}{ Maio/87 } \\
\hline & $M$ & $\mathrm{~F}$ & $J$ & M & $\mathrm{F}$ & $\mathrm{J}$ & M & $\mathrm{F}$ & J & M & $\mathrm{F}$ & J \\
\hline Porphyra & . & - & . & . & - & - & * & * & • & . & - & - \\
\hline U/va & 0,11 & 0,26 & 0,50 & . & - & 0,03 & 0.01 & . & 0,13 & * & * & * \\
\hline Padina & • & $\cdot$ & $\cdot$ & - & . & - & - & - & $\cdot$ & - & - & - \\
\hline Sargassum & - & - & - & - & . & 0,07 & - & - & 0,02 & 0,02 & 0.07 & 0,08 \\
\hline Gelidium & - & $\cdot$ & 0,02 & $\cdot$ & $\cdot$ & - & $\cdot$ & $\cdot$ & - & $\cdot$ & - & - \\
\hline Pterocladia & - & - & - & - & 0,10 & 0,33 & 0,13 & 0,28 & 0,76 & - & . & - \\
\hline Pterosiphonia & 0,39 & 0,20 & 1,12 & $\cdot$ & $\cdot$ & 0,15 & $\cdot$ & 0,63 & 1,99 & 0,48 & $\cdot$ & - \\
\hline Gymnogongrus & - & - & - & - & . & - & 0,24 & & - & & 0,36 & 0,92 \\
\hline
\end{tabular}

*. Algas não registradas.

Gelidium, uma das algas menos ramificadas e com o menor coeficiente de adsorção e peso de sedimento, mostrou uma fauna de ocorrência casual, tanto de Gammaridea como de Caprellidea.

Pterocladia se mostrou altamente favorável à colonização de Caprella penantis e de Hyale media. O grau de ramificação e o peso de sedimento intermediários e alto coeficiente de adsorção foram os fatores favoráveis a estas

Revta bras. Zool. 12 (2): 373 - 396, 1995 
Tabela VI. Hyale media. Densidade $\left(n^{\circ}\right.$ ind. $\left.g^{-1}\right)$ de machos $(M)$, fêmeas $(F)$ e juvenis $(J)$ dos fitais de Caiobá nas amostras de agosto/86, novembro/86, março/87 e maio/87.

\begin{tabular}{|c|c|c|c|c|c|c|c|c|c|c|c|c|}
\hline \multirow{2}{*}{ Fital } & \multicolumn{3}{|c|}{ Agosto/86 } & \multicolumn{3}{|c|}{ Novembro/86 } & \multicolumn{3}{|c|}{ Março/87 } & \multicolumn{3}{|c|}{ Maio/87 } \\
\hline & M & $\mathrm{F}$ & J & $M$ & $\mathrm{~F}$ & J & $M$ & $\mathrm{~F}$ & $J$ & $M$ & $\mathrm{~F}$ & J \\
\hline Porphyra & $\cdot$ & $\cdot$ & - & - & - & - & * & $*$ & $\cdot$ & $*$ & $*$ & * \\
\hline U/va & 0,06 & 0,23 & 0,22 & 0,05 & - & 0,06 & 0,07 & 0,07 & - & - & $\cdot$ & * \\
\hline Padina & $*$ & $*$ & $*$ & - & - & - & - & - & - & - & - & - \\
\hline Sargassum & 2,03 & 2,01 & 1,65 & 0,72 & 1,44 & 2,86 & 1,36 & 1,30 & 2,35 & - & 0,09 & 0,15 \\
\hline Gelidium & - & 0,12 & 0,27 & 0,13 & 0,92 & 0,89 & 0,09 & 0,12 & 0,42 & 0,05 & 0,26 & 0.06 \\
\hline Pterocladia & 1,35 & 2,47 & 3,06 & $\cdot$ & 1,07 & 2,41 & 0,91 & 1,75 & 1,64 & 1,80 & 2,85 & 8,79 \\
\hline Pterosiphonia & 2,92 & 3,94 & 7,60 & 1,01 & 2,32 & 31,46 & 9,22 & 13,41 & 20,43 & - & 8,42 & 4,32 \\
\hline Gymnogongrus & 0,35 & 2,06 & 2,80 & - & 0,96 & 1,37 & 14,23 & 16,40 & 34,98 & - & - & 3,10 \\
\hline
\end{tabular}

*. Algas não registradas.

Tabela VII. Hyale sp.1. Densidade $\left(\mathrm{n}^{\circ}\right.$ ind. $\left.\mathrm{g}^{-1}\right)$ de machos (M), fêmeas (F) e juvenis (J) dos fitais de Caiobá nas amostras de agosto/86, novembro/86, março/87 e maio/87.

\begin{tabular}{|c|c|c|c|c|c|c|c|c|c|c|c|c|}
\hline \multirow{2}{*}{ Fital } & \multicolumn{3}{|c|}{ Agosto/86 } & \multicolumn{3}{|c|}{ Novembro/86 } & \multicolumn{3}{|c|}{ Março/87 } & \multicolumn{3}{|c|}{ Maio/87 } \\
\hline & $M$ & $\mathrm{~F}$ & J & M & $\mathrm{F}$ & $J$ & M & $\mathrm{F}$ & $J$ & M & $F$ & $J$ \\
\hline Porphyra & - & 0,17 & - & 0,37 & $\cdot$ & - & ${ }^{*}$ & $*$ & $*$ & " & * & $*$ \\
\hline Ulva & - & 0,04 & - & 0,17 & 0,81 & - & 1,82 & 1,08 & 0,47 & • & • & * \\
\hline Padina & * & $*$ & * & 1,03 & 3,61 & 1,94 & 2,68 & 4,53 & 1,45 & 5,00 & 12,50 & 2,50 \\
\hline Sargassum & - & 0,02 & - & $\cdot$ & - & - & - & $\cdot$ & - & - & - & 0,05 \\
\hline Gelidium & - & - & - & . & - & . & - & - & - & . & - & - \\
\hline Pterocladia & $\cdot$ & - & - & - & - & . & 0,13 & 0,35 & 0,28 & - & - & - \\
\hline Pterosiphonia & - & - & - & $\cdot$ & - & - & - & - & - & - & 1,30 & 0,50 \\
\hline Gymnogongrus & - & 0,41 & - & - & - & - & - & - & - & 2,56 & 1,79 & 1,11 \\
\hline
\end{tabular}

${ }^{*}$. Algas não registradas.

Tabela VIII. Jassa falcata. Densidade $\left(\mathrm{n}^{\circ}\right.$ ind. $\left.\mathrm{g}^{-1}\right)$ de machos (M), fêmeas (F) e juvenis (J) dos fitais de Caiobá nas amostras de agosto/86, novembro/86, março/87 e maio/87.

\begin{tabular}{|c|c|c|c|c|c|c|c|c|c|c|c|c|}
\hline \multirow{2}{*}{ Fital } & \multicolumn{3}{|c|}{ Agosto/86 } & \multicolumn{3}{|c|}{ Novembro/86 } & \multicolumn{3}{|c|}{ Março/87 } & \multicolumn{3}{|c|}{ Maio/87 } \\
\hline & M & $\mathrm{F}$ & $\mathrm{J}$ & M & $\mathrm{F}$ & $J$ & $M$ & $\mathrm{~F}$ & $J$ & M & $\mathrm{F}$ & $J$ \\
\hline Porphyra & - & - & - & - & - & - & * & * & * & * & * & * \\
\hline Ulva & - & & - & & - & - & - & - & - & * & $*$ & * \\
\hline Padina & * & * & * & - & - & - & - & - & - & - & - & - \\
\hline Sargassum & $\cdot$ & $\cdot$ & 0,05 & $\cdot$ & - & 1,41 & $\cdot$ & - & 0,07 & - & - & 0,06 \\
\hline Gelidium & $\cdot$ & - & - & $\cdot$ & - & - & $\cdot$ & - & - & $\cdot$ & $\cdot$ & $\cdot$ \\
\hline Pterocladia & - & 1,00 & 3,68 & - & - & - & $\cdot$ & - & - & 0,05 & 0,46 & 0,70 \\
\hline Pterosiphonia & . & - & - & - & - & 0,29 & - & - & - & - & - & - \\
\hline Gymnogongrus & - & - & - & - & - & 0,38 & - & - & - & 0,75 & 3,25 & 9,95 \\
\hline
\end{tabular}

${ }^{*}$. Algas não registradas.

duas espécies. Ocorreram ainda outras quatro espécies, totalizando seis.

Em Gymnogongrus foram registradas sete espécies e, juntamente com Pterosiphonia e Pterocladia, constituiu o mais importante substrato para Hyale media (a mais alta densidade do presente estudo). Jassa falcata, também, foi numericamente expressivo nesta alga-substrato. 
Tabela IX. Sunampithoe pelagica. Densidade $\left(n^{\circ}\right.$ ind. $\left.\mathrm{g}^{-1}\right)$ de machos $(M)$, fêmeas (F) e juvenis(J) dos fitais de Caiobá nas amostras de agosto/86, novembro/86, março/87 e maio/87.

\begin{tabular}{|c|c|c|c|c|c|c|c|c|c|c|c|c|}
\hline \multirow{2}{*}{ Fital } & \multicolumn{3}{|c|}{ Agosto/86 } & \multicolumn{3}{|c|}{ Novembro/86 } & \multicolumn{3}{|c|}{ Março/87 } & \multicolumn{3}{|c|}{ Maio/87 } \\
\hline & $M$ & $\mathrm{~F}$ & $\mathrm{~J}$ & M & $\mathrm{F}$ & $\mathrm{J}$ & $M$ & $\mathrm{~F}$ & $\mathrm{~J}$ & $M$ & $\mathrm{~F}$ & $\mathrm{~J}$ \\
\hline Porphyra & - & - & - & - & . & . & • & . & * & . & . & • \\
\hline Ulva & . & - & - & - & - & . & - & - & - & , & $*$ & * \\
\hline Padina & • & $*$ & * & - & - & - & - & - & - & · & · & - \\
\hline Sargassum & 0,02 & 0.13 & 0,47 & 0,03 & 0,32 & 0,62 & 0,05 & 0,05 & 0,15 & 0,01 & 0,32 & 0,26 \\
\hline Gelidium & . & . & . & . & - & . & . & - & . & . & - & - \\
\hline Pterocladia & - & . & - & - & . & - & - & - & . & . & . & - \\
\hline Pterosiphonia & . & . & - & - & - & - & - & . & . & - & . & - \\
\hline Gymnogongrus & . & . & . & . & . & . & . & . & . & - & & - \\
\hline
\end{tabular}

*. Algas não registradas.

Tabela X. Caprella danileviskii. Densidade $\left(\mathrm{n}^{\circ}\right.$ ind. $\left.\mathrm{g}^{-1}\right)$ de machos (M), fêmeas (F) e juvenis(J) dos fitais de Caiobá nas amostras de agosto/86, novembro/86, março/87 e maio/87.

\begin{tabular}{|c|c|c|c|c|c|c|c|c|c|c|c|c|}
\hline \multirow{2}{*}{ Fital } & \multicolumn{3}{|c|}{ Agosto/86 } & \multicolumn{3}{|c|}{ Novembro/86 } & \multicolumn{3}{|c|}{ Março/87 } & \multicolumn{3}{|c|}{ Maio/87 } \\
\hline & $M$ & $\mathrm{~F}$ & J & $M$ & $\mathrm{~F}$ & $\mathrm{~J}$ & $M$ & $\mathrm{~F}$ & $J$ & $M$ & $F$ & J \\
\hline Porphyra & - & - & - & - & - & - & * & * & * & $*$ & * & $\cdot$ \\
\hline Ulva & - & - & - & - & - & - & - & - & - & * & * & * \\
\hline Padina & * & $*$ & * & - & - & - & - & - & - & - & - & - \\
\hline Sargassum & 0,04 & 0.17 & 0,02 & 0,36 & 2,11 & 0,19 & - & 0,09 & - & - & - & \\
\hline Gelidium & 0,19 & 1,45 & 0,32 & 0,06 & 0,18 & - & - & - & . & - & 0,03 & 0,01 \\
\hline Pterocladia & 0,26 & 0,65 & 0,64 & - & 0,42 & - & - & - & - & . & - & 0,09 \\
\hline Pterosiphonia & - & 1,56 & 1,56 & $=$ & 0,23 & 0,19 & - & - & - & - & - & - \\
\hline Gymnogongrus & - & - & - & - & - & - & - & - & - & - & - & - \\
\hline
\end{tabular}

*. Algas não registradas.

Tabela XI. Caprella penantis. Densidade $\left(n^{\circ}\right.$ ind. $\left.\mathrm{g}^{-1}\right)$ de machos (M), fêmeas (F) e juvenis (J) dos fitais de Caiobá nas amostras de agosto/86, novembro/86, março/87 e maio/87.

\begin{tabular}{|c|c|c|c|c|c|c|c|c|c|c|c|c|}
\hline \multirow{2}{*}{ Fital } & \multicolumn{3}{|c|}{ Agosto/86 } & \multicolumn{3}{|c|}{ Novembro/86 } & \multicolumn{3}{|c|}{ Março/87 } & \multicolumn{3}{|c|}{ Maı/87 } \\
\hline & M & $\mathrm{F}$ & J & M & $F$ & J & M & $\mathrm{F}$ & J & M & $F$ & $\mathrm{~J}$ \\
\hline Porphyra & - & . & - & . & - & - & $*$ & * & * & $\cdot$ & $\cdot$ & $\cdot$ \\
\hline U/va & - & & - & & . & - & & . & . & . & * & $\cdot$ \\
\hline Padina & * & • & * & $\cdot$ & - & - & & - & $\cdot$ & . & - & \\
\hline Sargassum & - & 0,02 & - & 0,02 & 0,16 & & & & 0,04 & - & . & \\
\hline Gelidium & 0.02 & 0,04 & 0,07 & · & - & - & - & - & - & - & - & - \\
\hline Pterocladia & 3,40 & 22.62 & 4,93 & - & 0,52 & 0,65 & - & - & - & 0.13 & 4,25 & 1.23 \\
\hline Pterosiphonia & 0,07 & 3,63 & 5,85 & 0,16 & 2,07 & 0,83 & & 0,28 & . & & · & 0,33 \\
\hline Gymnogongrus & - & 1,20 & 0,41 & · & - & 0,18 & - & - & - & . & 0,92 & - \\
\hline
\end{tabular}

${ }^{*}$. Algas não registradas.

\section{Os AMPHIPODA GAMMARIDEA}

Foram coletados 4511 Gammaridea, dos quais 1218 foram obtidos em agosto, 1378 em novembro, $1451 \mathrm{em}$ março e 464 em maio. Com exceção de Cymadusa filosa, todos Gammaridea ocorreram nas quatro datas de coleta. A distribuição de densidade destas espécies nos diversos fitais, nas quatro coleta: 
realizadas está representada graficamente nas figuras 3 e 4 . Os fitais foram ordenados na abscissa obedecendo a sequência das algas foliáceas seguidas das ramificadas e, dentre estas, as menos seguidas das mais ramificadas (Fig. 2). As tabelas III a XI tratam da densidade de adultos e juvenis e a tabela XII, a proporção de sexos dos Amphipoda.

Tabela XII. Amphipoda dos fitais de Caiobá. Número absoluto (N) de machos (M) e fêmeas (F) adultos de Amphipoda e a proporção (Prop.) de sexos nas amostras de agosto/86, novembro/86, março/87 e maio/87.

\begin{tabular}{|c|c|c|c|c|c|c|c|c|c|c|c|c|}
\hline \multirow{3}{*}{ Amphipoda } & \multicolumn{3}{|c|}{ Agosto/86 } & \multicolumn{3}{|c|}{ Novembro/86 } & \multicolumn{3}{|c|}{ Março/87 } & \multicolumn{3}{|c|}{ Maio/87 } \\
\hline & \multicolumn{2}{|c|}{ N } & \multirow{2}{*}{$\frac{\text { Prop. }}{M: F}$} & \multicolumn{2}{|c|}{ N } & \multirow{2}{*}{$\frac{\text { Prop. }}{M: F}$} & \multicolumn{2}{|c|}{ N } & \multirow{2}{*}{$\frac{\text { Prop. }}{M: F}$} & \multicolumn{2}{|c|}{$N$} & \multirow{2}{*}{$\frac{\text { Prop. }}{J}$} \\
\hline & $M$ & $\mathrm{~F}$ & & M & $F$ & & $M$ & $\mathrm{~F}$ & & $M$ & $\mathrm{~F}$ & \\
\hline Ampithoe ramondi & 4 & 13 & $1: 3$ & 1 & 5 & $1: 5$ & - & 1 & - & - & 4 & $\cdot$ \\
\hline Cymadusa filosa & 2 & 2 & $1: 1$ & - & - & - & - & - & - & - & - & - \\
\hline Elasmopus pectenicrus & 6 & 13 & $1: 2$ & - & 1 & - & 5 & 10 & $1: 2$ & 4 & 6 & $1: 1$ \\
\hline Hyale media & 253 & 283 & $1: 1$ & 73 & 223 & $1: 3$ & 230 & 440 & $1: 2$ & 24 & 98 & $1: 4$ \\
\hline Hyale sp. 1 & - & 5 & - & 4 & 13 & $1: 3$ & 31 & 21 & $1: 1$ & 8 & 18 & $1: 2$ \\
\hline Jassa falcata & - & 17 & - & - & - & $\cdot$ & - & - & · & 2 & 8 & $1: 4$ \\
\hline Sunampithoe pelagica & 2 & 10 & $1: 5$ & 1 & 17 & $1: 17$ & 1 & 1 & $1: 1$ & 1 & 10 & $1: 10$ \\
\hline Caprella danileviskii & 25 & 199 & $1: 8$ & 40 & 164 & $1: 4$ & - & 2 & $\cdot$ & - & 5 & - \\
\hline Caprella penantis & 41 & 333 & $1: 8$ & 7 & 35 & $1: 5$ & - & - & - & 5 & 50 & $1: 10$ \\
\hline
\end{tabular}

Ampithoe ramondi apresentou as maiores densidades em agosto, quando foi encontrado em quatro fitais: Gymnogongrus (1,91 ind. $\left.\mathrm{g}^{-1}\right)$, Ulva $\left(0,32\right.$ ind. $\left.\mathrm{g}^{-1}\right)$, Sargassum $\left(0,05\right.$ ind. $\left.\mathrm{g}^{-1}\right)$, e Gelidium $\left(0,02\right.$ ind. $\left.\mathrm{g}^{-1}\right)$. Em março ocorreu apenas em Pterosiphonia com 0,1 lind.g $\mathrm{g}^{-1}$. Não houve constância de presença em qualquer fital e esteve ausente em Porphyra e Padina no período de coleta (Fig. 3). Maior proporção de adultos foi registrada no fital Ulva, em contraste com o de Gymnogongrus, onde juvenis predominaram fortemente sobre os adultos. Isto sugere que, os talos foliáceos de Ulva teriam favorecido a fixação dos tubos dos adultos. Os juvenis, devido ao tamanho reduzido, mostraram preferência pela alga ramificada (Tab. III). Uma fêmea ovígera foi registrada em agosto e outra em março.

Cymadusa filosa foi registrada apenas em Gymnogongrus e Ulva em agosto e em Pterosiphonia em maio. A maior densidade ocorreu em Ulva em agosto $(1,14$ ind. $g^{-1}$ ) (Fig. 3). Os juvenis constituíram o maior contingente da população de agosto e $100 \%$ da de maio (Tab. IV).

Elasmopus pectenicrus foi constante somente em Pterosiphonia e Ulva. Temperaturas altas devem favorecer a população, pois, em março foram registradas a densidade máxima (2,62 ind. $\mathrm{g}^{-1}$ em Pterosiphonia) e a presença na maioria dos fitais analisados (Fig. 3). Houve forte predominância de juvenis nos fitais de talos finamente ramificados (Tab. V). Apenas uma fêmea ovígera foi registrada.

Hyale media foi a espécie mais abundante, totalizando 1570 indivíduos e perfazendo 34,28\% dos Gammaridea registrados. De um modo geral, Gymnogongrus, Pterosiphonia e Pterocladia foram as algas-substrato preferidas pela espécie, cujas densidades máximas atingiram 65,60 ind. $\mathrm{g}^{-1}$ (março), 43,07 ind. $\mathrm{g}^{-1}$ (março) e 13,44 ind.g ${ }^{-1}$ (maio), respectivamente. Com exceção de maio/87, ocorreu em densidades intermediárias em Sargassum e baixas em Ulva e Gelidium. 
Ampithoe ramondi

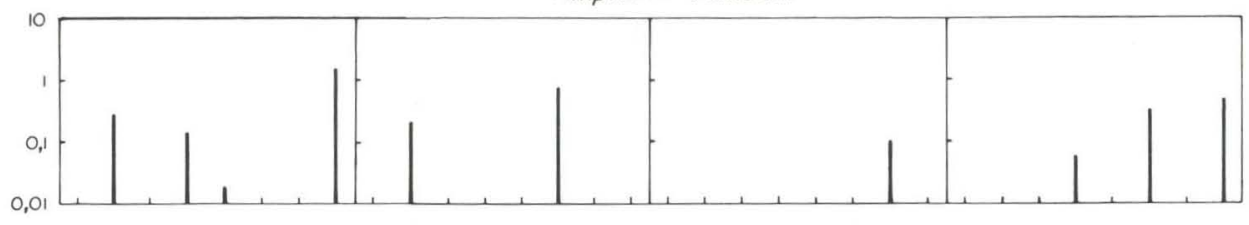

Cymadusa filoso
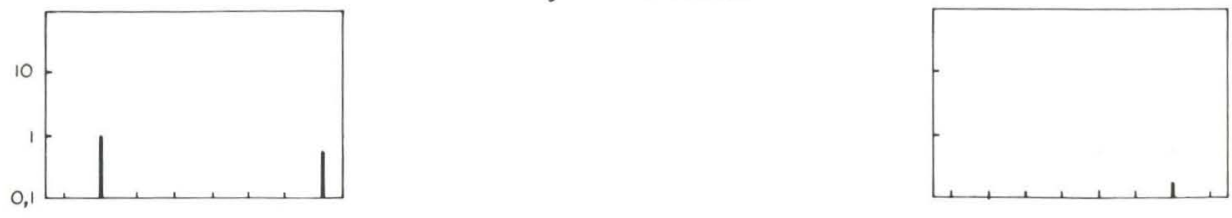

Elosmopus pectenicrus

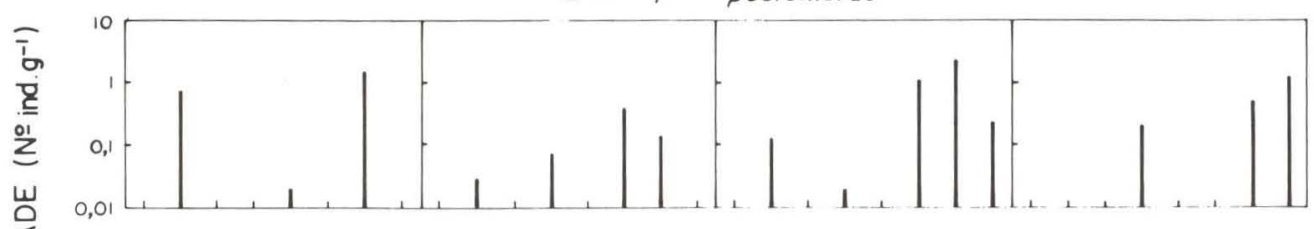

Hyale media

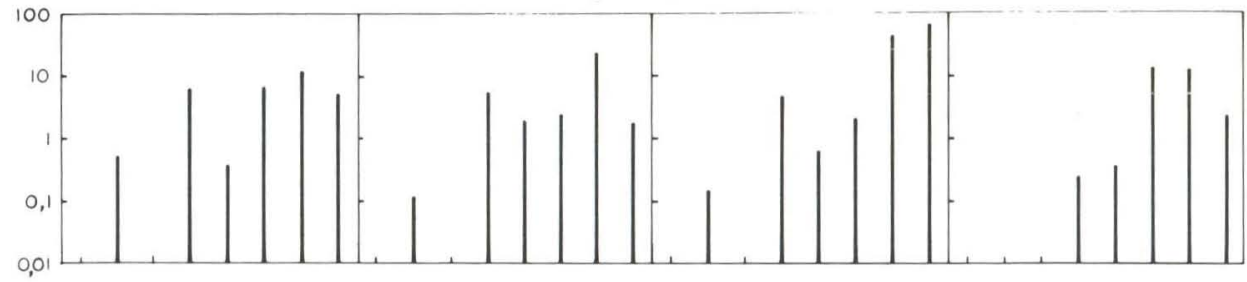

Hyale sp I

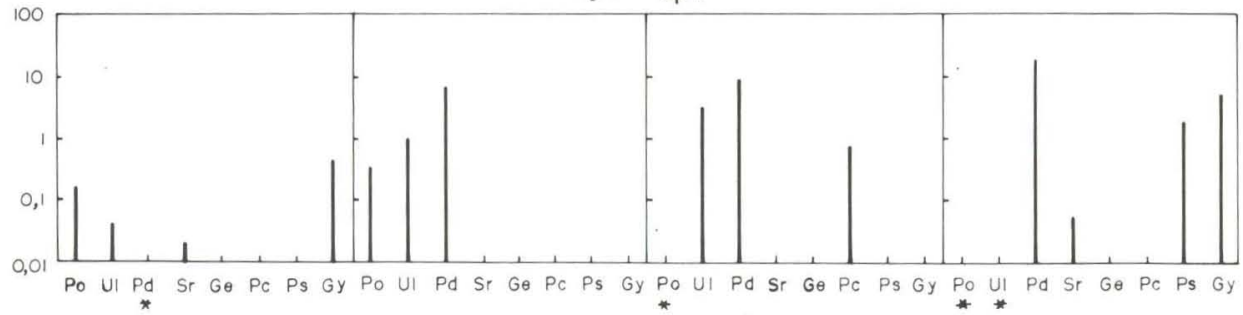

Fig. 3. Distribuição de densidade dos Amphipoda nos fitais estudados, nas quatro coletas realizadas. Os fitais estão dispostos na abscissa na sequência das algas-substrato com talos foliáceos seguidas das ramificadas e, dentre estas, as menos seguidas das mais ramificadas. (Po) Porphyra, (UI) Ulva, (Pd) Padina, ( $\mathrm{Sr}$ ) Sargassum, (Ge) Gelidium, (Pc) Pterocladia, (Ps) Pterosiphonia, (Gy) Gymnogongrus, $\left({ }^{*}\right)$ alga-substrato não registrada.

Revta bras. Zool. 12 (2): 373 - 396, 1995 
Esteve ausente em Padina e Porphyra.

Pterosiphonia, Pterocladia e Gymnogongrus que possuem altos coeficientes de adsorção, abrigaram maior número de $H$. media. As menores densidades foram registradas em Gelidium enquanto que em Sargassum as densidades foram sempre intermediárias, exceto em maio, mês muito chuvoso. Já em alg̣as de talo foliáceo, apesar do alto coeficiente de adsorção, $H$. media ocorreu sempre em baixas densidades ou esteve até mesmo ausente. Estes fatos sugerem que a forma da alga-substrato juntamente com o coeficiente de adsorção são fatores que determinam a abundância de $H$. media nos fitais estudados. Como a quantidade de sedimento está relacionada com o coeficiente de adsorção dentre as algas ramificadas, pode-se inferir que, o fator sedimento esteja contribuindo, também, para a abundância deste Amphipoda.

Como as maiores densidades de $H$. media foram registradas nas amostras de março, seguido de novembro, agosto e maio, pode-se dizer que, valores mais elevados de temperatura e salinidade favorecem a reprodução e/ou abundância destes animais. Corroboram com esta assumpção, a forte predominância de juvenis sobre os adultos nas amostras de março e novembro. Fêmeas, quase sempre, foram mais numerosas que os machos (Tab. VI).

Hyale sp.l esteve presente em todos os fitais, à exceção de Gelidium. Ocorreu em todas as amostras de Porphyra, Ulva e Padina, algas de talo foliáceo (Fig. 3). Foi a única espécie de Amphipoda registrada no fital Padina no período estudado, com forte predominância em todos os meses de coleta em que esta alga foi registrada: em novembro com 6,58 ind. $\mathrm{g}^{-1}$, em março com 8,66 ind. $\mathrm{g}^{-1}$ e em maio om 20,00 ind. $\mathrm{g}^{-1}$. Estas densidades podem estar relacionadas com a quantidade máxima de sedimento registrada em Padina, onde ocorreram predominantemente adultos (Fig. 2). Corrohoram esta hipótese, altas densidades em Porphyra e Ulva (agosto, novembro e março) e em Pterosiphonia e Gymnogongrus (maio), algas com altos valores de sedimento retido.

Hyale spp. é um agrupamento constituído exclusivamente por juvenis de tamanho reduzido, provavelmente de $H$. media e Hyale sp. 1. Ocorreu em todos os fïtais com exceção de Porphyra, Padina e Gelidium. Valores altos de densidades foram registrados em Pterosiphonia em todas as coletas, atingindo o máximo em março com 23,40 ind. $g^{-1}$ (Fig. 4). Aparentemente, algas finamente ramificadas favorecem o povoamento destes animais de pequeno porte.

Jassa falcata apresentou-se constante apenas em Sargassum. A densidade máxima registrada em Gymnogongrus em maio (13,95 ind. $\left.\mathrm{g}^{-1}\right)$ é devida ao recrutamento de juvenis na população (Tah. VIII) e, indica que este fital oferece talos ramificados de tamanho adequado aos juvenis. Pterocladia, também, desempenhou o mesmo papel em agosto e em maio. Esteve ausente em Porphyra, Ulva e Gelidium (Fig. 4).

Sunampithoe pelagica ocorreu exclusivamente em Sargassum (Fig. 4), cuja densidade máxima foi registrada em novembro $\left(1,16\right.$ ind. $\left.\mathrm{g}^{-1}\right)$ e a mínima em março $\left(0,21\right.$ ind. $\left.g^{-1}\right)$. De presença constante em todas a coletas do ano, os juvenis predominaram sobre os adultos, exceto em maio (Tab. IX). 
Hyale spp

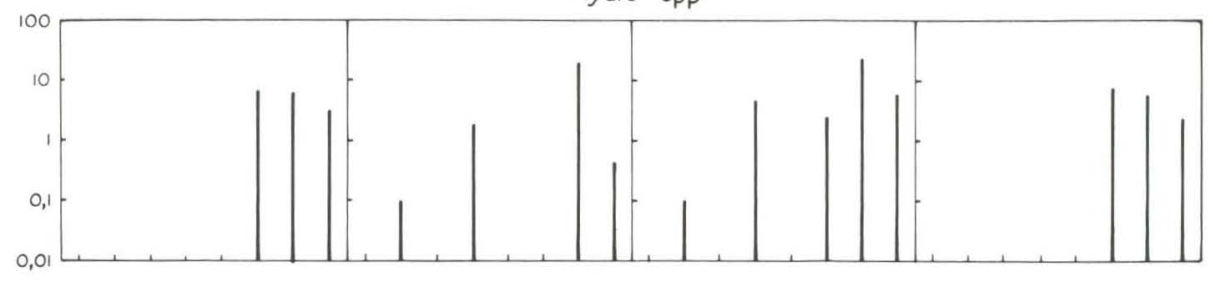

Jassa falcata

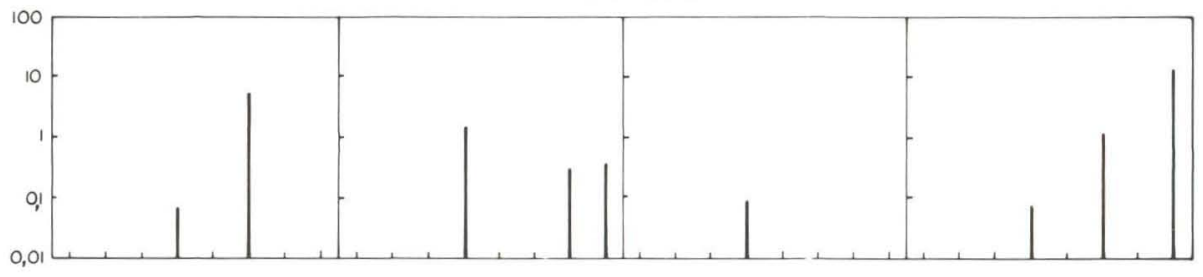

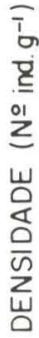

Sunampithoe pelagica

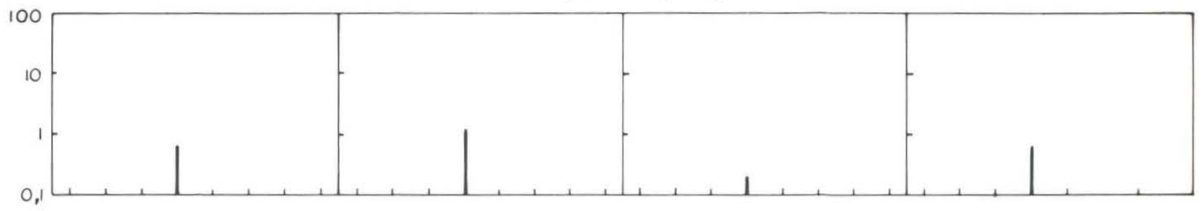

Caprella danilevskii

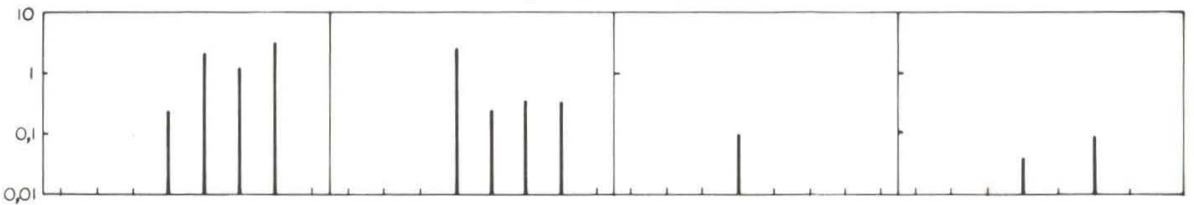

Caprella penantis

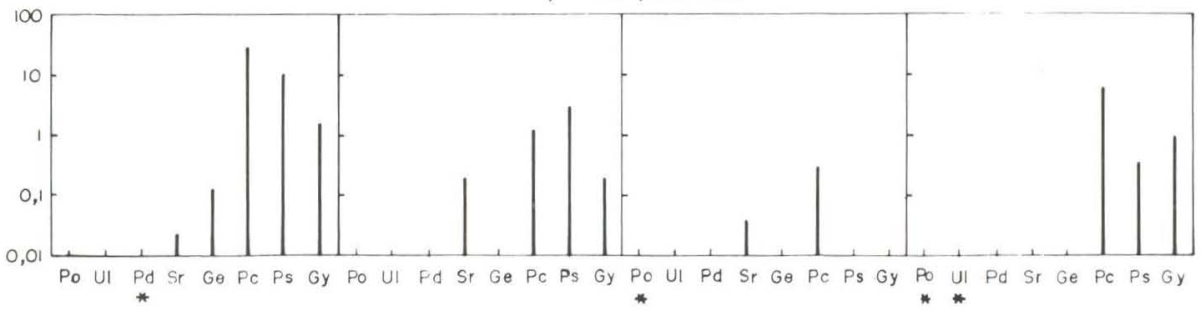

Fig. 4. Distribuição de densidade dos Amphipoda nos fitais estudados, nos quatro meses de coleta. Os fitais estão dispostos na abscissa na sequência das algas-substrato com talos foliáceos seguidas das ramificadas e, dentre estas, as menos seguidas das mais ramificadas. (Po) Porphyra, (UI) Ulva, (Pd) Padina, ( $\mathrm{Sr}$ ) Sargassum, (Ge) Gelidium, (Pc) Pterocladia, (Ps) Pterosiphonia, (Gy) Gymnogongrus, $\left({ }^{*}\right)$ alga-substrato não registrada. 


\section{Os Amphipoda Caprellidea}

Foram coletados 1185 Amphipoda Caprellidea, dos quais 820 foram obtidos em agosto, $280 \mathrm{em}$ novembro, sete em março e $78 \mathrm{em}$ maio. A distribuição de densidade nos diversos fitais está na figura 4.

Caprella danilevskii ocorreu exclusivamente em algas ramificadas; a espécie esteve presente, com as maiores densidades do ano, nas quatro (Sargassum, Gelidium, Pterocladia e Pterosiphonia) das cinco algas ramificadas registradas em agosto. A máxima ocorreu em Pterosiphonia $\left(3,12\right.$ ind.g $\left.{ }^{-1}\right)$ e a mínima em Sargassum $\left(0,23\right.$ ind. $\left.\mathrm{g}^{-1}\right)$. Em novembro, embora em densidades menores, este Caprellidae ocorreu nos mesmos fitais registrados em agosto; a maior densidade foi de 2,67 ind. $\mathrm{g}^{-1}$ em Sargassum e a menor foi de 0,17 ind. $\mathrm{g}^{-1} \mathrm{em}$ Gelidium. Em março, esta espécie foi registrada apenas em Sargassum $\left(0,09\right.$ ind. $\left.\mathrm{g}^{-1}\right)$ e em maio em Pterocladia $\left(0,09\right.$ ind. $\left.\mathrm{g}^{-1}\right)$ e Gelidium $\left(0,04\right.$ ind. $\left.\mathrm{g}^{-1}\right)$ (Fig. 4).

Caprella danilevskii apresentou um padrão de flutuação de densidade com um pico máximo em agosto e valor mínimo em março; como não foi registrado nas algas foliáceas, a ramificação do substrato pode ser um fator essencial no povoamento pelo Amphipoda. Por outro lado, a ausência de $C$. damilevskii na alg̣a densamente ramificada Gymnogongrus (menor distância média entre uma ramificação e outra, dentre todas as algas estudadas) indica yue o tamanho do espaço disponível entre as ramificações do talo das algas é um fator limitante para a presença da espécie: valores altos e médios de distância das ramificações parecem favorecer o povoamento. Como Pterosiphonia e Gymnogongrus não são significativamente diferentes quanto ao grau de ramificação, a presença deste Amphipoda naquele fital pode ser interpretada como consequência da diferença na consistência do talo das duas algas-substrato (compare a figura $2 \mathrm{com}$ a figura 4 ). Em agosto e em novembro, houve maior proporção de juvenis do que de adultos em Pterosiphonia sugerindo uma atividade de recrutamento de juvenis neste fital. As fêmeas foram muito mais numerosas do que os machos nas proporções de 1:8 (agosto) e de 1:4 em novembro (Tab. X).

Caprella penantis, como a espécie anterior, esteve ausente nas algas foliáceas e, em agosto, este Amphipoda foi registrado em todas as algas ramificadas; houve um pico de abundância nesta época do ano, quando, a maior densidade ocorreu em Pterocladia (30,95 ind. $\mathrm{g}^{-1}$ ) seguida de Pterosiphomia $(9,55$ ind. $\left.g^{-1}\right)$, Gymmogongrus $\left(1,61\right.$ ind. $\left.g^{-1}\right)$. Gelidium $\left(0,13\right.$ ind. $\left.g^{-1}\right)$ e Sargassum $(0,02$ ind. $g^{-1}$ ). Em novembro ocorreu nos mesmos titais de agosto, com exceção de Gelidium, porém, em densidades bem mais haixas do que no mês anterior (exceto em Sargassum cujo valor foi de 0,17 ind. $\mathrm{g}^{-1}$ ). Em março, C. penantis foi registrado apenas em Pterosiphonia e Sargassum com densidades de 0,04 ind.g $^{-1}$ e 0,28 ind. $g^{-1}$, respectivamente, ao passo que, em maio, esteve presente em Pterocladia (5,96 ind. $\left.\mathrm{g}^{-1}\right)$, Pterosiphonia $\left(0,33\right.$ ind. $\left.\mathrm{g}^{-1}\right)$ e Gymnogongrus $\left(0,92\right.$ ind. $\left.\mathrm{g}^{-1}\right)$. Nota-se assim, um padrão de distribuição temporal de densidade caracterizado por um pico máximo em agosto decrescendo em novembro, atingindo níveis mínimos em março e voltando a aumentar em maio.

Caprella penantis esteve presente em todas os meses de coleta apenas em 
Pterosiphonia, com densidades variando entre 9,55 ind. $\mathrm{g}^{-1}$ (agosto) e 0,28 ind. $\mathrm{g}^{-1}$ (março). Porém, o maior valor de densidade foi registrado em Pterocladia em agosto $\left(30,95\right.$ ind $\left.\mathrm{g}^{-1}\right)$. Nos fitais com altas densidades deste Amphipoda, houve forte dominância de adultos sobre os juvenis em Pterocladia (agosto e março) e uma situação oposta em Pterosiphonia (agosto). Estes dados indicam que adultos e juvenis têm necessidades diferentes quanto ao tamanho do espaço disponível entre os talos ramificados. Dentre os adultos, as fêmeas foram mais numerosas do que os machos, nas proporções de 1:8 (agosto), 1:5 (novembro) e 1:10 (maio); em março, houve apenas três fêmeas (Tab. XI).

A figura 5 mostra a distribuição das densidades médias de adultos e de juvenis de todas as espécies de Amphipoda registradas em cada tital no período de estudo. Houve uma distribuição diferenciada de acordo com o grau de ramificação da alga-substrato. Juvenis predominaram nas algas mais finamente ramificadas Pterosiphonia e Gymnogongrus, enquanto os adultos foram mais abundantes nas algas foliáceas - Porphyra, Ulva e Padina. Por outro lado, nas algas de talos robustos e menos ramificadas - Sargassum, Gelidium e Petrocladia - não se verificaram diferenças significativas entre as densidades de adultos e juvenis.

Ainda, analisando-se as espécies de maior contribução com as densidades de adultos em cada fital, verifica-se que Hyale media, cujos exemplares são os de menor tamanho dentre os Amphipoda registrados, foi a predominante nas algas finamente ramificadas. Nas algas com talos menos ramificados, além de $H$. media, houve contribuição significativa de espécies de maior tamanho como $C$. penantis (em Petrocladia), C. danilevskii (em Sargassum e Gelidium). Em contrapartida, nas algas foliáceas, as maiores densidades de adultos devem-se a Hyale sp. 1, cujos exemplares apresentam tamanhos maiores, quando comparados a $\mathrm{H}$. media.

\section{DISCUSSÃO E CONCLUSÕES}

Segundo Joly (1965), Porphyra ocorre principalmente no final do outono, no inverno e na primavera. Durante os meses de verão torna-se praticamente inexistente devido a uma alternância estacional entre suas fases tïlamentosa e foliácea. Isto explica a ausência desta alga nos meses correspondentes ao outono e verão do presente estudo. O mesmo autor, também, afirma que Ulva, embora melhor desenvolvida em certos meses, pode ser encontrada em qualquer época do ano, sob a forma de pequenas plantas com altura de poucos centímetros. Em Caiobá, o seu peso úmido na amostra de verão (março) foi nitidamente inferior ao das amostras de inverno (agosto) e primavera (novembro), o que revela uma diminuição no comprimento de suas frondes durante o verão. Entretanto, a falta de registro desta alga em maio (outono) não implica necessariamente em sua ausência total nos costões rochosos, pois, esta coleta foi prejudicada pelo tempo chuvoso e pela altura da maré que não atingiu o nível previsto. Aliado a este fator, a intensa atividade extrativa de Ulva pelo homem foi visível nesta época do ano.

A variação nos valores de densidade de Amphipoda nos diversos fitais de Caiobá de acordo com a forma e grau de ramificação concorda com os estudos de 


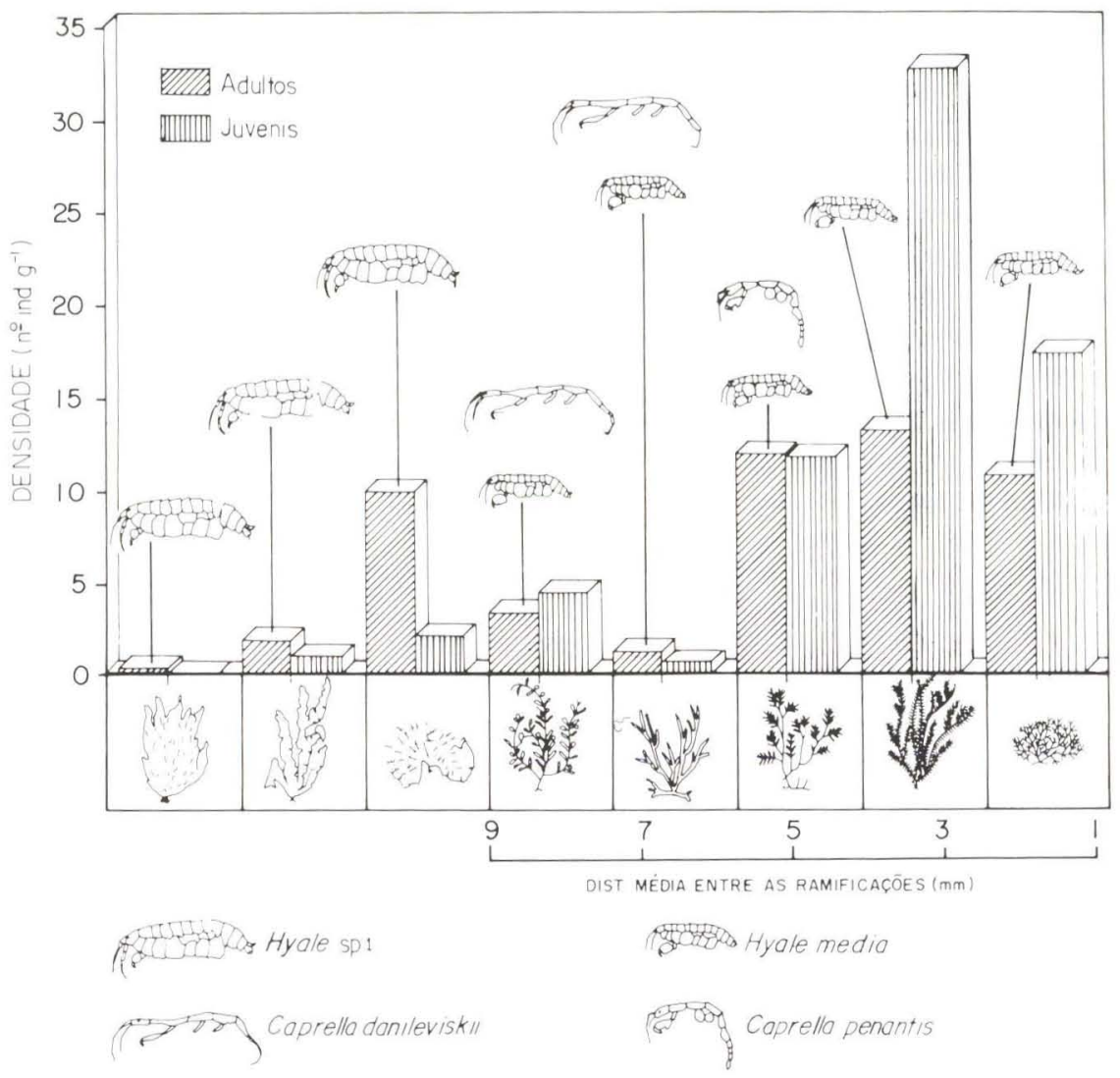

Fig. 5. Fitais de Caiobá. Distribuição de densidade de adultos e juvenis das espécies de Amphipoda registradas nos diversos fitais durante todo o período de estudo. Somente os amphipoda mais abundantes foram desenhados nos fitais em que ocorreram mais de uma espécie. Legenda para as algas-substrato (da esquerda para a direita): Porphyra, Ulva, Padina, Sargassum, Gelidium, Pterocalidia, Pterosiphonia, Gymnogongrus.

WIESER (1951) que, numa análise de 18 espécies de algas sob iguais condições ambientais, demonstrou que o número de animais que habitam algas com diferentes graus de ramificação está diretamente relacionado com os seus coeficientes de adsorção. Entretanto, para as algas de talo foliáceo, esta correlação não é válida, visto que Porphyra e Ulva, apesar dos altos valores de coeficiente de adsorção, mostraram as mais baixas densidades de Amphipoda. Por outro lado, Padina, apesar do talo foliáceo, mostrou o maior peso de sedimento de todos os fitais, certamente, devido à presença de pelos microscópicos na superfície do talo (JOLY 1967). As altas densidades do Amphipoda Hyale sp. 1 registradas neste fital são um fato inédito e concordam, em parte, com as conclusões de WIESER (1952) e DAHL (1948) de que, maior quantidade de sedimento rico em detritos resulta em uma fauna mais numerosa. Entretanto, a exclusividade em abrigar somente este 
Amphipoda neste tital pode ser explicada por uma possivel repartiçăo do recurso habitat entre as expecies do genero Hyale (SCHOENER 1974).

O baixo peso de sedimento retido em Ulia associado à forma foliáced de seu talo, limitando o espaço disponivel entre as frondes. explica as haxas densidades e até mesmo a ausência de muitas espécies de Amphipoda nos fitais de Caiohá.

Todas as espécies de Amphipoda identificadas no presente estudo já foram registradas em algas (KRAPP-SCHICKEL 1969; BARNARD 1969a,b: TARARAM \& WAKABARA 1981: MASUNARI 1982: TARARAM (' al. 1986).

Das sete espécies de Gammaridea registradas em Caiohá. seis já foram encontradas em Samgasum c ymosum no litoral paulista. Contudo, o numero total de espécies registradas no referido fital foi superior, sendo $16 \mathrm{em}$ Uhatuba (TARARAM \& WAKABARA 1981) e $13 \mathrm{em} \mathrm{Itanhaém} \mathrm{(TARARAM} \mathrm{1986).} \mathrm{Quatro}$ destas espécies, também, foram assinaladas na llha das Palmas. São Paulo. para Amphiroa beauvoisii: Ampithoe ramondi. Elasmopus pectenicrus. Hyale media e Jassa falcata (MASUNARI 1982). Estes dados, entretanto, nào permitem inferir que os fitais de Caiohá tenham menor riqueza de espécies do que os de São Paulo, já que a amostragem no presente estudo se limitou à zona entremarés, excluindo o infralitoral onde, provavelmente, maior número de espécies de Amphipoda teria sido registrado.

Espécies tuhicolas como Ampithoe ramondi requerem material para a construção de seus tubos (MonRE 1973), o que está relacionado à movimentação amena da água e à quantidade de sedimento disponivel. Esta espécie predominou em locatis protegidos, com acúmulo de sedimento e. em níveis inferiores no fital Amphiroa beawoisii (MASUNARI 1982). As haixas densidades de Ampithoe rannondi em Caiohá podem estar relacionadas à movimentação intensa da água do local de coleta e/ou ocorrência preferencial em locais de maior profundidade. Por outro lado, a presença de Ampithoe ramondi em fitais do mediolitoral superior como a $U /$ la no presente estudo, parece estar mais relacionada com a cohertura epitítica (SCHNEIDER \& MANN 199la.h).

Jassa falcalla, também, um Gammaridea tubícola (BARNARD 1969h), é mais ahundante em locais agitados, já que seus fortes gnatópodos estão adaptados a se prender firmemente às algas (NAGLE 1968; Mox)RE 1973). Os dados do presente estudo sugerem que esta espécie ocorreria em densidades mais altas com o aumento da profundidade como toi ohservado por DAHL (1948). WIESER ( 1952). MASUNARI (1982) e TARARAM et al. (1986). uma vez yue. a ag̨itação da ąg̨ta não teria sido um fator limitante para a mesma.

Sunampithoe pelagica é conhecida como uma espécie pouco comum em algas (KRAPP-SCHICKEL 1969) e abundante em Sargassum flutuantes (TRUCHOT 1963). A baixa densidade deste Amphipoda e a sua preferência por Sargassum foram ohservadas, também, em Itanhaém (São Paulo) onde for reģistrada somente nos níveis inferiores do mediolitoral exclusivamente em duas espécies de Sargassum (WAKABARA el al. 1983).

A ocorrência de Elasmopus pectenicrus, aparentemente, não é influenciada pela forma da alga-suhstrato como foi observada nos fitais de Caiohá, tampouco 
a sua distrihuição vertical segue qualq̣uer padrão) (MASUNARI 1982: TARARAN et al. 1986).

Seģundo SToNER (1980), a predação constitui o principal fator yue limita o tamanho das populaçóes de Amphipoda e segundo NELSON (1980). onde há predadores pode-se predizer que os Amphipoda infaunais serão as espécies mais abundantes seguidas pelas tuhícolas e, as epifaunais de vida livre as menos abundantes. Em Caiohá, das espécies de Amphipoda presentes, apenas très são tubicolas e ocorreram em haixas densidades: A. ramondi, C. filosa e J. falcata. As demais são de vida livre e, dentre elas, $H$. média é a espécie dominante. Estes fatos sugerem que a predação não é um fator importante na regulação das densidades dos Amphipoda nos fitais de Caiohá. A favor desta hipótese, vários autores (NELSON 1980; VAN DOLAH 1978: MUKal 1971) consideram yue os Amphipoda são presas fáceis para os predadores que utilizam a visão (peixes e Decapoda, por exemplo) e o tamanho da presa pode ser, desta forma, um importante fator na seleção. Em Caiohá, a predação, pelo menos utilizando mecanismos visuais, deve ser um recurso hastante limitado, pois segundo JoLy (1951), a transparência da água é quase nula, principalmente na haixa-mar. devido à grande quantidade de material organo-argiloso trazidos dos manguesais próximos. Por outro lado, as haixas densidades de $A$. ramondi, C. filosa, $S$. pelagica, $J$. falcata e E. pectenicrus nestes fitais (do mediolitoral) podem estar relacionadas. principalmente, ao fato destes animais não suportarem grandes períodos de emersão, o que corrobora os dados ohtidos por TARARAM et al. (1986).

WIESER (1952), SARMA \& GANAPATI (1970) e TARARAM el al. (1985) afirmam que espécies de Hyale estão bem adaptadas a viver entre as algas dos níveis superiores do litoral. H. media apresenta uma ampla distribução vertical no mediolitoral. mas com valores de densidade mais elevados em algas de consistência macia (TARARAM et al. 1985), fato observado também por MCBANE \& CROCKER (1983) em H. nilssomi.

HACKER \& STENECK (1990) encontraram densidades de Gammarus angulosus significativamente maiores em algas ramificadas ou filamentosas quando comparadas às algas de talo foliáceo. Para os autores, os volumes intersticial e do talo das algas são os principais fatores yue regulam a abundância do Amphipoda estudado. Isto explica a tendência verificada no presente estudo de haver maiores densidades de Hyale media, Caprella damilesskii e $C$. penamis nas algas ramificadas do que nas de talo foliáceo e, dentre as ramificadas. nas de maior coeficiente de adsorção. AoKI \& KIKUCHI (1990) estudaram várias espécies de Caprellidea que habitam algas e hidróides. Caprella penantis não apresentou preferência por hahitat, enquanto que Caprella demilesskii foi registrado apenas em hidróides. Este comportamento foi associado à morfologia destes animais: exemplares de $C$. penamtis encontrados em hidróides apresentaram o própodo do pereópodo VII menor e com menos setas na sua palma do que os registrados em algas. $C$. danilesskii apresentou o corpo mais delgado e longo do que $C$. penamris e, seu pereópodo VII com o própodo mais delicado.

Segundo TAKEUCHI et al. (1987) a distribuição de $C$. damilewkii. dentre várias algas, esteve limitada às de fronde com comprimento maior que dez 
centímetros, enquanto que $C$. penantis não apresentou limitações em sua distribuição nas diferentes espécies de algas. Os autores também relacionaram estas diferenças de distribuição à morfologia dos Amphipoda. Caprella danilesskii foi observado se agarrando estendido ao longo do talo das algas, utilizando seus gnatópodos I e pereópodos V, VI e VII. Já as espécies de Caprellidea exclusivas de algas menores, utilizavam somente os três últimos pereiópodos para se prenderem à algá, ficando numa posição ereta.

No presente trabalho, a ausência de C. danilevskii em Gymnogongrus pode ser explicada pela altura reduzida do talo e/ou espaço insuficiente entre as ramificações para oferecer abrigo ao Amphipoda. Em contrapartida, C. penantis que foi registrado em todas as algas, mas com densidade máxima em Pterocladia (agosto), parece procurar abrigo em algas de valores intermediários de espaço entre as ramificações. A favor desta assumpção, DUTRA (1988) registra as maiores densidades desta espécie em Pterocladia capillacea. A ausência dos Caprellidea em algas de talo foliáceo no presente estudo indica que estas não são substratos adequados para estes animais de hábito agarrador.

Assim, pode-se inferir que, devido a fatores morfológicos (forma do corpo e apêndices) associados à estrutura das algas, $C$. penantis apresenta uma maior plasticidade na escolha de seus habitats do que $C$. danilevskii, contirmando os dados de TAKEUCHi et al. (1987).

Foi observado em muitos fitais que as estações do ano parecem influenciar somente a densidade de povoamento e não o número de espécies que neles vivem (HAGERMAN 1966; MuKaI 1971). Esta afirmação parece ser válida, também, para os titais de Caiobá, pois as espécies de Amphipoda, à exceção de Cymadusa filosá, foram observadas nos quatro meses de amostragem. A maior ahundância de $H$. media na amostra correspondente ao outono coincide, em parte, com os dados de TARARAM \& WAKABARA (1981) para $S$. cymosum onde as maiores densidades foram registradas em dezembro e março. O grande aumento de densidade de $C$. penantis em agosto nos fitais de Caiobá coincide com os trabalhos de CAINE (1983) e Dutra (1988), mas discorda com o de MASUnari (1982).

A literatura não contempla o estudo da distribuição etária dos Amphipoda em fitais. No presente trabalho, foi constatado que a maioria das espécies de Amphipoda tem as algas finamente ramificadas como local de desenvolvimento dos juvenis, mesmo que os adultos habitem algas foliáceas. A distribuição temporal de densidade dos Amphipoda pode estar relacionada com a flutuação da intensidade da atividade reprodutiva das espécies que é contínua no ano. As fêmeas são mais numerosas do que os machos na maioria das espécies, como ocorre com a maioria dos Peracarida dos fitais.

Os dados do presente estudo confirmam a necessidade de conservação dos bancos de fitais de Caiobá, pois, os mesmos mostraram ser um ecossistema hastante complexo, onde os Amphipoda realizam integralmente o seu ciclo de vida. Experimentos de predação em lahoratório, provavelmente, virão confirmar que as populações de Amphipoda estudadas constituem um importante recurso alimentar para os animais de níveis tróticos superiores, incluindo os de importância comercial. 
AGRADECIMENTOS. À Profa Dra Yoko Wakahara (Instituto Oceanográfico. Universidade de São Paulo) pela confirmação das identificaçōes dos Amp̧hipoda. Ao Prof. Dr. Ayrton de Mattos (in memorian) e ao M. Se. José Augusto Cunha (Departamento de Boxânica, Universidade Federal do Paraná), pela identificação das algas do presente estudo.

\section{REFERÊNCIAS BIBLIOGRÁFICAS}

AOKI, M. \& T. KIKUCHI. 1990. Habitat adaptations of caprellid amphipods and the importance of epiphytic secondary habitats in a Sargassum patens bed in Amakusa, Southern Japan. Publ. Amakusa Mar. Biol. Lah. 10 (2): 123-133.

BARnARD, J.L. 1969a. Gammaridean Amphipoda of the rocky intertidal of California: Monterey Bay to La Jolla. Bull. U.S. Nat. Mus. 258: 1-230. 1969b. The families and genera of marine gammaridean Amphipoda. Bull. U.S. Nat. Mus. 271: 1-535.

Brawley, S. \& X.G. FEY. 1987. Studies of mesoherbivory in aquaria and in an unbarricaded mariculture farm on the Chinese coast. J. Phycol. 23: 614-623.

CAINE, E.A. 1983. Community interactions of Caprella penantis Leach (Crustacea Amphipoda) on sea whips. J. Crustacean Biol. 3 (4): 497-504.

DAHL, C. 1948. On the smaller Arthropoda of marine algae, especially in the polyhaline waters off the Swedish West coast. Untersuchung Oresund 35: 1-193.

DhN. 1986. Tábua das marés. Diretoria de Hidrografia e Navegação, Marinha do Brasil, 224p.

1987. Tábua das marés. Diretoria de Hidrografia e Naveg̨ação, Marinha do Brasil, 224p.

DUFFY, J.E. 1990. Amphipods on seaweeds: partners or pests? Oecologia 8: 267-276.

DutRA, R.R.C. 1988. A fauna vágil do fital Pterocladia capillacea (Rhodophyta Gelidiaceae) da Ilha do Mel, Paraná, Brasil. Rev. Bras. Biol. 48 (3): 589-605.

GibBons, M.J. 1988a. The impact of wave exposure on the meiofauna of Gelidium pristoides (Turner) Kuetzing (Gelidiales: Rhodophyta). Estuarine, Coastal Shelf Sci. 27: 581-593.

1988b. Impact of predation by juvenile Climus superciliosus on phytal meiofauna. Are fish important as predators? Mar. Ecol. 45 (1-2): 13-22.

HACKER, S.D. \& R.S. STENECK. 1990. Hahitat architecture and body-sizedependent habitat selection of a phytal amphipod. Ecology 71 (6): 2269-2285.

Hagerman, L. 1966. The macro and microfauna associated with Fucus serratus L. with some ecological remarks. Ophelia 3: 1-43.

Hay, M.E.; J.E. Duffy; C.A. Pfister \& W. Fenical. 1987a. Chemical defense against different herbivores: are amphipods and insect equivalents? Ecology 68: $1567-1580$.

Hay, M.E.,;W. Fenical \& K. Gustafson. 1987b. Chemical defense against diverse coral-reef herbivores. Ecology 68: 1581-1591.

Hay, M.E.; V.J. Paul; S.M. Lewis; K. Gustafson; J. Tucker \& R. TRindell. 
1988a. Can tropical seaweeds reduce herhivory by growing at night? Diel patterns of growth, nitrogen contend herhivory, and chemical versus morphological defenses. Oecologia, Berlim, 75: 233-245.

Hay, M.E.; P.E. REnAud \& W. FEnICAL. 1988h. Large mohile versus small sedentary herbivores and their resistance to seaweed chemical defenses. Oecologia (Berlim) 75: 246-252.

JAKoBI, H. 1954. Espécies novas de Harpacticoidea (Copepoda Crustacea) encontradas nas algas marinhas do litoral do Paraná e Santa Catarina. Bol. Inst. Oceanogr. 5 (1-2): 189-212.

- 1962. Harpacticoidea e Syncarida troglobiontes (Crustacea). Bol. Univ. Paraná, Zool., I (21): 1-19.

JoLy, A.B. 1951. Contribuição para o conhecimento da flora algológica marinha do Estado do Paraná. Bol. Inst. Oceanogr. 2 (1): 125-138.

1965. Flora marinha do litoral norte do estado de São Paulo e regiões circunvizinhas. Bol. Fac. Filos. Ciênc. Let. Univ. São Paulo 294, Ser. Bot., 21: 1-393.

1967. Gêneros de algas marinhas da costa atlantica latino-americana. Editora da Universidade de São Paulo, São Paulo, 461 p.

KIKUCHI, T. \& J.M. PÉRÈs. 1977. Consumer ecology of seagrass beds, p. 147-193. In: C.P. MCRoy \& C. HelfFerich (eds). Seagrass Ecossystem. New York. M. Dekker, 314p.

Krapp-Schickel, V.G. 1969. Zur Oekologie der Amphipoden aus dem Phytal der Nordadria. Zool. Jh. Syst. 96 (3): 265-448.

LEWIS, F.G. III. 1987. Crustacean epifauna of seagrass and macroalga in Apalachee Bay. Florida, USA. Mar. Biol. 94 (2): 219-229.

Loyola E Silva, J. 1960. Sphaeromatidae do litoral hrasileiro. Bol. Univ. Paraná, Zool., 4: 1-182.

Masunari, S. 1982. Organismos do fital Amphiroa heauvoisii Lamouroux, 1816 (Rhodophyta; Corallinaceae). I. Autoecologia. Bol. Zool. Univ. S. Paulo 7: $57-148$.

1986. Copepoda Harpacticoidea dos fitais do litoral do Paraná. Ciênc. Cult. 38 (7): 1010.

- 1987. Ecologia das Comunidades Fitais, p. 195-233. In: Academia de Ciências do Estado de São Paulo (ed.). Simpósio sohre ecossistemas da costa sul e sudeste brasileira. Cananéia, 459p.

Masunari, S. \& L. Forneris. 1981. O ecossistema fital - uma revisão, p. 149172. In: Academia Brasileira de Ciências (ed.). Seminários de Biologia Marinha. Rio de Janeiro, 383p.

Mazzella, L.; M.B. Scipione \& M.C. BuiA. 1989. Spatio-temporal distribution of algal and animal communities in a Posidonia oceanica meadow. Mar. Ecol. 10 (2): 107-129.

MCBANE, C.D. \& R.A. CRoCKer. 1983. Animal-algae relationships of the amphipod Hyale nilssoni (Ratke) in the rocky interdital. J. Crustacean Biol. 3: $592-601$. 
Moxre, P.G. 1973. The larger Crustaced associated with holdfast of kelp (Lamimaria hypertorea) in North-East Britain. Cah. Biol. Mar. I4 (4): 493-518.

Mukal, H. 1971. The phytal animals on the thalli of Sargassum serratifolium in the Sargaxum region, with reference to their seasonal fluctuations. Mar. Biol. 8: $170-182$.

NAGLE, J.S. 1968. Distrihution of the epibiota of macroepihenthic plants. Contrib. Mar. Sci. 13: 105-144.

NELSoN, W.G. 1980. The hiology of eelgrass (Zostera marina) amphipods. Crustaceana 39 (1): 59-88.

Nonato, E.F. \& J.M. PÉrÈs. 1961. Observations sur quelques pleuplements intertidaux de suhstrat dur dans la région dUbatuba (État de São Paulo). Cah. Biol. Mar. 2 (3): 263-270.

Oliveira-Filho, E.C. \& E.M. Mayal. 1976. Seasonal distribution of intertidal organisms at Uhatuba, São Paulo (Brasil). Rev. Bras. Biol. 36: 305-316.

RYER, C.H. 1988. Pipefish foraging: effects of fish size, prey size and altered hahitat complexity. Mar. Ecol. Prog. Ser. 48 (1): 37-45.

Ryer, C.H. \& R.J. ORTh. 1987. Feeding Ecology of the Northern pipefish, Syngnathus fuscus, in a seagrass community of the lower Cheasapeake Bay. Estuaries 10 (4): 330-336.

SARMA, A.L.N. \& P.N. GanapaTI. 1970. Faunal associations of algae in the intertidal region of Visakhapatnam (India). Proc. Indian Nat. Sci. Acad. 38 : 380-396.

SCHNEIDER, F.I. \& K.H. MANN. 1991a. Species specific relationships of invertehrates to vegetation in a seagrass bed. I. Correlational studies. J. Exp. Mar. Biol. and Ecol. 145: 101-117.

1991h. Species specific relationships of invertehrate to vegetation in a seagrass bed. II. Experiments on the importance of macrophyte shape, epiphyte cover and predation. J. Exp. Mar. Biol. Ecol. 145: 119-139.

SCHOENER, T.W. 1974. Resource partitioning in ecological communities. Science $185(4145): 27-39$.

STONER, A.W. 1980. Abundance, reproductive seasonality and hahitat preferences of amphipod crustaceans in seagrass meadows of Apalachee Bay, Florida. Contrih. Mar. Sci. 23: 63-77.

Takeuchi, I.; R. Kuwabara; R. Hirano \& H. Yamakawa. 1987. Studies on the compositions of the Caprellidea (Crustacea: Amphipoda) of the Sargassum zone on the pacific coast of Japan. Bull. Mar. Sci. 41(2): 253-267.

TARARAM, A.S. \& Y. WAKABARA. 1981. The mohile fauna - especially Gammaridea - of Sargasimn cymosum. Mar. Ecol. Prog. Ser. 5: 157-163.

TARARAM, A.S.; Y. WAKABARA \& F.P.D. LeITE. 1985. Feeding habits of Hycile media (Dana, 1953) (Crustacea-Amphipoda). Bol. Inst. Oceanogr. 33 (2): 193-199.

1986. Vertical distribution of amphipods living on algae of a Brazilian intertidal rocky shore. Crustaceana 51 (2): 183-187. 
Truchot, J.P. 1963. Étude faunistique et écologique des amphipodes des facies rocheux intertidaux de Roscòff. Cah. Biol. Mar. 4: 121-176.

VAN DoLAH, R.F. 1978. Factors regulating the distribution and population dynamics of the amphipod Gammarus palustris in an intertidal salt marsh community. Ecol. Monogr. 48: 191-217.

Wakabara, Y.; A.S. TARARAM \& A.M. TAKEDA. 1983. Comparative study of the amphipod fauna living on Sargassum of two Itanhaém shores, Brazil. J. Crustacean Biol. 3 (4): 602-607.

WIESER, W. 1951. Ueber die quantitative Bestimmung der Algenhewohnenden Mikrofauna felsiger Meerekuesten. Oikos 3 (1): 124-131. . 1952. Investigations on the microfauna inhabiting seaweeds on rocky coasts. IV. Studies on the vertical distribution of the fauna inhabiting seaweeds below the Plymouth Laboratory. J. Mar. Biol. Ass. U.K. 31: 145-174. 